\title{
A new tool for the drying time and the moisture risk estimation in concrete floors
}

\author{
Pauli Sekki ${ }^{1, *}$, Pasi Marttila ${ }^{2}$, and Tarja Merikallio $^{3}$ \\ ${ }^{1}$ Vahanen Building Physics Ltd, Finland \\ ${ }^{2}$ PAJU Applications, Finland \\ ${ }^{3}$ Concrete Association of Finland
}

\begin{abstract}
Moisture management in building site has improved significantly in recent years. However, problems with concrete floors are repeatedly found. One possible reason for the failure may be that the time required for adequate drying of the concrete has not been properly considered when scheduling the building process and because the pressure to complete the building, the floor covering has been installed too early. In building industry, there is a clear need for better understanding of the adequate drying times of concrete structures, as well as tools to make sufficient drying estimates. The new tool BY2020 provides a new approach to drying and moisture risk estimations. The simulation tool is a FEM-based model that allows change in geometry with time so that the material layers are automatically added into the model, based on the determined schedule. The boundary conditions are also changing with time based on the schedule. In addition, the water vapor resistance of the flooring material can be modelled to evaluate the long-term moisture behavior of the floor structure. Preliminary results are encouraging and the feedback on the new approach has been positive. Validation process is ongoing and target completion time for the tool is late 2020.
\end{abstract}

\section{Introduction}

Demands for moisture management in Finnish building industry have increased and moisture safety is emphasized at every step of the building process. In particular, moisture management in building site has improved significantly in recent years. However, problems with concrete floors are repeatedly found. In some cases, the moisture content of concrete has been too high prior to floor covering. This might have been due to poor moisture control at the site. It is possible that the time required for adequate drying of the concrete has not been properly considered when scheduling the building process and due to the pressure to complete the building, the floor covering has been installed too early. This, in turn, may be because the owner determines the completion time and the contractor may have to promise an unrealistic schedule in order to obtain the contract. To solve this problem, owners and contractors need a better understanding of the adequate drying times of concrete structures, as well as tools to make a sufficient drying estimate.

Almost twenty years old Excel based spreadsheet method [1] called BY1021 has been widely used in preliminary drying time estimations of young concrete floor structures in Finland. The main disadvantages of this method are the limited choices for structures and for drying conditions. In addition, the water vapor resistance of the flooring material is not taken into account. BY2020 is a new tool for estimating drying time and moisture risk in concrete floors and it provides estimations that are more accurate. The simulation tool is a FEM-based model that allows change in geometry with time so that the material layers are automatically added into the model, based on the determined construction schedule. The boundary conditions are also changing with time based on the determined schedule. In addition, the water vapor resistance of the flooring material can be modelled to evaluate the long-term moisture behavior of the floor structure. The new tool provides the opportunity for more accurate moisture-safe design. The development of the computational model is still ongoing. The model will be validated based on field measurements, especially with respect to the drying time estimation. The target completion time for the tool is late 2020. The aim of this paper is to introduce the new tool for the drying time and the moisture risk estimation in concrete floors.

\section{Overview of the calculation tool}

\subsection{Application technology}

The new calculation tool BY2020 simulation application contains two core application layers, Finite Element Method (FEM) based physical model for solving heat and moisture transfer in transient manner and the Graphical User Interface (GUI) to help end user to control the underlying FEM model. The FEM model has all different modeling scenarios built-in, like different boundary conditions, material properties and geometrical options. The GUI part has been built considering user friendliness but also high technical standards at the same

\footnotetext{
*Corresponding author: pauli.sekki@vahanen.com
} 
time. The end user's input will be delivered to the FEM model and the application rebuilds and solves the model based on this interaction. Results are then plotted to the graphics window and simulation report will be generated on request. The whole application has been built with COMSOL Multiphysics simulation environment with build-in Application Builder tools to create interactive user interfaces with predefined user interface objects and handwritten java methods. The public release of the application will be deployed as a standalone software where the simulation application will be compiled with COMSOL Compiler. The application will be also available as a cloud based server application by using COMSOL Server technology.

\subsection{Heat and moisture transfer}

Heat and moisture transfer is governed by a system of two partial differential equations for the energy and mass balance. Hydration reactions of concrete are described by heat source and moisture sink terms, where the degree of hydration is dependent of the equivalent age of concrete.

\subsection{Concrete material model}

Material properties of concrete are modeled based on the concrete recipe and the calculation models presented in the literature. The hydration of the concrete is influenced by of quantities e.g. binder (total content), water and aggregate. The moisture properties change over the calculation, depending on the degree of hydration, temperature and relative humidity.

\subsection{Analysis types}

The calculation tool includes two types of analysis, which can be used to evaluate the drying time of a concrete floor structure or the performance of a structure after floor covering with moisture risk estimation. Structures are selected from a pull-down menu, with alternatives of slab on ground, crawl space base or an intermediate floor structure. The slab on ground structure is a plastic foam insulated (EPS / XPS) on a cast-in-situ structure. The structures of the base floor with crawl space and intermediate floor are:

- Hollow core slab with a surface concrete

- Hollow core slab with a screed

- Precast slab with a load bearing surface concrete

- Cast-in-situ slab (drying in one or two directions)

- Concrete slab with multiple layers, cast-in-situ

- Precast slab with a surface concrete In addition, a screed or insulation (EPS / PIR al / mineral wool) can be placed on the structure. For hollow core and precast slabs, computation begins with the structural concrete casting. The humidity of the precast substructure is chosen to correspond to the moist concrete. Depending on the structure, the concrete grade can be selected from different ready-mixed floor concrete (FC) and structural concrete (SC) grades shown in Table 1.
Conditions prior to the drying period are considered according to the exterior climate data (ASHRAE 2017) [2]. Thus, time of year will be taken into account and therefore the timing of construction will affect the estimate. The temperature is limited to $>5^{\circ} \mathrm{C}$, assuming that the casting is not carried out under freezing conditions.

Wetting can be taken into account by using the optional period, in which the structure is covered with a water layer throughout the selected period. Thus, the worst-case scenario can be estimated.

The drying condition is determined as a constant condition. The end of humid outdoor condition and the beginning of the drying period are determined from the time of casting. When determining the drying conditions of a structure, the completion schedule of the structural layers should also be planned; installation of the surface layers is also determined from the structural concrete casting.

Table 1. Available concrete grades in BY2020.

\begin{tabular}{|l|l|l|l|}
\hline $\begin{array}{l}\text { Concrete } \\
\text { grade }\end{array}$ & $\begin{array}{l}\text { Product } \\
\text { range }\end{array}$ & $\begin{array}{l}\text { Compressive } \\
\text { strength }\end{array}$ & $\begin{array}{l}\text { Water - } \\
\text { binder ratio }\end{array}$ \\
\hline FC1 & normal & $\mathrm{C} 25 / 30$ & 0.73 \\
\hline FC2 & $\begin{array}{l}\text { faster } \\
\text { coating }\end{array}$ & $\mathrm{C} 25 / 30$ & 0.55 \\
\hline FC3 & normal & $\mathrm{C} 30 / 37$ & 0.60 \\
\hline FC4 & $\begin{array}{l}\text { faster } \\
\text { coating }\end{array}$ & $\mathrm{C} 32 / 40$ & 0.47 \\
\hline $\mathrm{SC} 1$ & normal & $\mathrm{C} 25 / 30$ & 0.70 \\
\hline $\mathrm{SC} 2$ & $\begin{array}{l}\text { winter } \\
\text { grade }\end{array}$ & $\mathrm{C} 28 / 35$ & 0.50 \\
\hline
\end{tabular}

\subsection{Drying time estimation}

The structure and conditions are determined as described in section 2.3. No floor covering is determined.

The critical relative humidity $(\mathrm{RH})$ is placed at the measuring depth (A) which is adopted from Finnish guidelines for measurement of relative humidity in concrete structures [3]. The critical RH is dependent of the floor covering materials. However, the criterion of depth $0.4 * \mathrm{~A}<75 \% \mathrm{RH}$ must also be met.

\subsection{Moisture risk estimation}

In the risk assessment, the structure and conditions are determined as described in section 2.3. The water vapor resistance of the floor covering shall be determined.

Generally, the criteria for risk assessment are determined by the floor covering material manufacturers' instructions. Because material manufacturers often fail to provide their own guidelines, $85 \% \mathrm{RH}$ is considered to be critical for adhesives and plastic carpets [4] and therefore, could be used as a limit after floor covering. 


\section{Analysis case examples}

\subsection{Drying in one direction, low water-binder ratio}

One direction drying of concrete with low water-binder ratio $(w / b)$ is compared with recent study [COMBI], where concrete panel $(\mathrm{w} / \mathrm{c}<0,5)$ was insulated with vapour tight PIR insulation and drying of the concrete panel was monitored in laboratory conditions $\left(20^{\circ} \mathrm{C} / 50\right.$ $\%$ RH) [5]. Drying estimation was conducted using intermediate floor slab, cast-in-situ SC2 (w/b = 0,5). Results are shown in figure 1.

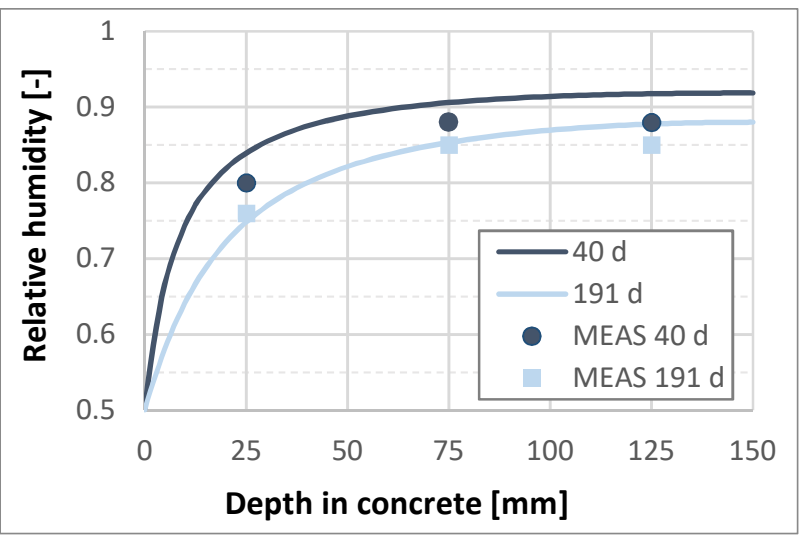

Fig. 1. Comparison of the moisture distribution of the estimate with the measurements.

\subsection{Drying in one and two direction}

One and two direction drying are compared with each other. Drying conditions are $20{ }^{\circ} \mathrm{C} / 50 \% \mathrm{RH}$. Drying estimation was conducted using intermediate floor slab, cast-in-situ. Results are shown in table 2.

Table 2. Drying time estimation.

\begin{tabular}{|l|l|l|l|}
\hline & $\begin{array}{l}\text { Concrete } \\
\text { grade }\end{array}$ & Drying & $\begin{array}{l}\text { Criterion } \\
\text { reached at }\end{array}$ \\
\hline Case 2.1 & SC1 & 1 -sided & $316 \mathrm{~d}$ \\
\hline Case 2.2 & SC1 & 2-sided & $100 \mathrm{~d}^{*}$ \\
\hline Case 2.3 & SC2 & 1 -sided & $240 \mathrm{~d}$ \\
\hline Case 2.4 & SC2 & 2-sided & $82 \mathrm{~d}$ \\
\hline
\end{tabular}

*Criterion $85 \% \mathrm{RH}$ at depth $\mathrm{A}$ is reached at 70 days

\subsection{Drying and moisture risk estimation}

Example case is an intermediate slab consisting of precast slab KL120 with a load bearing surface concrete $300 \mathrm{~mm}$ and $10 \mathrm{~mm}$ of low-alkaline screed. Options for concrete grades are SC1 and SC2. Building is located in Vantaa and casting is carried out the $1^{\text {st }}$ of August and leveling two weeks prior to installation of the floor covering. Structure is exposed to weather for 60 days and it is assumed to get wet between 30-60 days. In addition, the case without wetting was considered.
Drying conditions will be optimal $20^{\circ} \mathrm{C}$ and $50 \% \mathrm{RH}$. Criterion for evaluation depth A is $85 \% \mathrm{RH}$.

Results of the drying time estimation are shown in table 3. Screed was excluded from the drying estimation. However, the effect of the screed was considered in moisture risk estimation. Based on drying time estimation SC2 was selected and means to achieve tighter schedule was investigated. Installation of the screed was set to 280 days and floor covering two weeks thereafter. Drying condition and water vapor resistance of the floor covering was varied. Simulation period is three years. Result are shown in table 4 . Result view of the case 4.2 and the program interface is introduced in Figure 2.

Table 3. Drying time estimation.

\begin{tabular}{|l|l|l|l|}
\hline & $\begin{array}{l}\text { Concrete } \\
\text { grade }\end{array}$ & Wetting & $\begin{array}{l}\text { Criterion } \\
\text { reached at }\end{array}$ \\
\hline Case 3.1 & $\mathrm{SC} 1$ & $30-60 \mathrm{~d}$ & $405 \mathrm{~d}$ \\
\hline Case 3.2 & $\mathrm{SC} 2$ & $30-60 \mathrm{~d}$ & $349 \mathrm{~d}$ \\
\hline Case 3.3 & $\mathrm{SC} 2$ & - & $305 \mathrm{~d}$ \\
\hline
\end{tabular}

Table 4. Moisture risk estimation.

\begin{tabular}{|l|l|l|l|}
\hline & $\begin{array}{l}\text { Floor covering } \\
\text { sd }[\mathbf{m}]\end{array}$ & $\begin{array}{l}\text { Drying condition } \\
{\left[{ }^{\circ} \mathbf{C} / \text { \% RH] }\right.}\end{array}$ & $\begin{array}{l}\mathbf{R H}^{*} \\
{[\mathbf{\%}]}\end{array}$ \\
\hline Case 4.1 & 75 & $20 / 50$ & 84 \\
\hline Case 4.2 & 20 & $20 / 50$ & 82 \\
\hline Case 4.3 & 20 & $15 / 60$ & 85 \\
\hline
\end{tabular}

*beneath the floor covering at the end of the simulation period

\section{Discussion}

The comparison of drying of concrete in one direction with low water-binder ratio $(\mathrm{w} / \mathrm{b})$ with measurements in recent Finnish study shows a promising agreement with the estimation and measurements. In addition, it should be noted the error is on the safe side considering decisions to be conduct based on the estimation. In comparison of drying in one and two direction shows that the estimation the drying time in one direction is around three times longer comparing with drying in two directions. Results are consistent with the assumption that the difference between cases can be up to four times [6]. However, the challenge is to create the model so that the moisture distribution is consistent in every case. For example, in case 2.2 the criterion at depth $\mathrm{A}$ is reached at 30 days prior to criterion at depth $0,4^{*} \mathrm{~A}$ which is contrary to practical experience. In addition, the drying time estimations with BY1021 are roughly two times comparing to BY2020. Therefore, the need for validation of the BY2020 is obvious. One option is to change the interface so that the measured drying conditions and quality control RH measurement of the concrete could be uploaded into BY2020. 


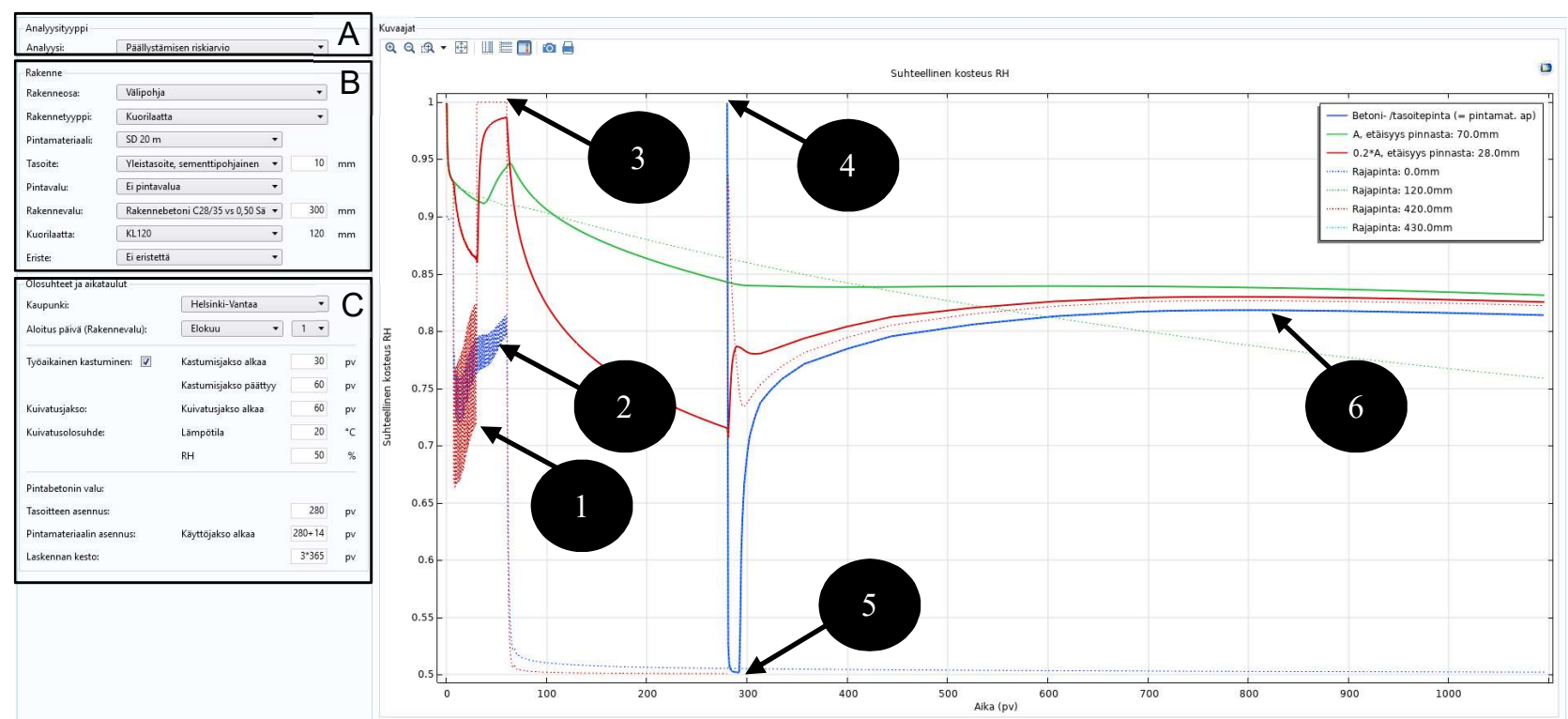

Fig. 2. Comparison of the moisture distribution of the estimate with the measurements. 1. RH above, 2. RH below, 3. Wetting period, 4. Applying of the screed, 5. Floor covering installation, 6. RH beneath the floor covering. A. Analysis type, B. Structure and material parameters, C. Conditions and schedule.

Thus, the data for validation would be available to developers. This allows data to be obtained from numerous construction sites. At a later stage, the same features can be utilized for quality control and documentation, enabling contractors to improve their practices.

The moisture risk estimation provides an opportunity to generate comparisons to reach the determined relative humidity beneath the floor covering. Owner can set the schedule and the level of moisture control based on simulation so that the critical factors have been taken into account from the start of the project. For example, a highly permeable floor covering may allow for a tighter schedule, while a water vapor tight plastic carpet with thick screed sets demanding requirements for weather protection and drying conditions. In addition, an overall order of magnitude is gained when assessing the importance of water vapor tightness of the floor coverings. As the water vapor resistance of plastic carpet floorings for public spaces varies between $s_{\mathrm{d}} 20$ and $75 \mathrm{~m}$, it can be estimated whether the choice of carpet type between 70 and $75 \mathrm{~m}$ is relevant to the moisture risk (see table 4).

Furthermore, the influence of drying temperature and wetting conditions can also be taken into account as well as the wetting effect of the screed and carpet glue. The feedback on the new approach has been positive.

There have been demands for updating the relative humidity limits and measuring depths. Based on preliminary simulations the current guidelines are mainly suitable. However, the measuring depths currently in use are determined for relatively permeable high $\mathrm{w} / \mathrm{b}$ concrete and water vapour tight plastic carpets. In contrast, the concrete with low water-cement ratio has significantly lower permeability. Particularly, if the w/b ratio is very low, the moisture transfer is minimal. It is important to assess whether the criteria shall be the same for different concrete grades. However, it is noted that the effect of the surface material should be taken into account when determining the critical relative humidity and measuring depths.

\section{Conclusions}

The new tool provides opportunities for more accurate moisture-safe design. The moisture performance of the whole structure can be evaluated instead of assessment of adequate drying of the plain concrete floor. As a result, the evaluation of the moisture performance of the concrete floors should consider:

- Water vapor permeability of floor covering.

- Humidity of the base structure (concrete and sublayers) and moisture transfer properties of the materials.

- Relevant RH criteria and measuring depths A and B (not necessarily linking between depths) of the specific concrete floor.

- Material actual ability to tolerate moisture without being damaged (determined by the floor covering material manufacturers').

Modeling drying of the concrete is very demanding and a wide variety of tests and measurement data from building sites are still required to validate the model. Nevertheless, BY2020 will be carefully validated; the user of the program should understand the effect of concrete grade and other variables in the program in drying; which factor influences in which direction. In addition, material actual ability to tolerate moisture without being damaged is still challenging to determine however, material manufacturers are expected to meet additional information needs.

From a quality control perspective, the new tool could change the RH criteria and measuring depths. Since virtually every concrete mix cast-in-situ is different and the conditions in sites are not equivalent to simulation, there is still a need for accurate $\mathrm{RH}$ measurements in building sites. 


\section{References}

1. T. Merikallio, Betonirakenteiden kosteusmittaus ja kuivumisen arviointi. Fourth edition, unchanged version, 58 (Betonikeskus ry, 2015)

2. Comsol, Heat Transfer Module User's Guide, 702 (2018)

3. RT 14-10984, Betonin suhteellisen kosteuden mittaus, 16 (Building Information Foundation RTS sr, 2010)

4. T. Merkikallio, S. Niemi, J. Komonen, Betonilattioiden kosteudenhallinta ja päällystäminen, 97 (Suomen betonitieto, 2007)

5. J. Vinha et. al, Comprehensive development of nearly zero-energy municipal service buildings (COMBI). Tutkimushankkeen johdanto-ja yhteenvetoraportti. Tutkimusraportti 168. 45+111 (2019)

6. G. Hedenblad. Fuktsäkerhet i byggnader. Uttorkning av byggfukt i betong - Torktider och fuktmätning, 54 (Byggforskningrådet T12,1995) 